\title{
Adenoid Cystic Carcinoma of the Trachea
}

\author{
Santhosh Kumar $\mathbf{N}^{1}$ • Elizabeth Mathew Iype ${ }^{1} \cdot$ Shaji Thomas $^{1}$ • Uma V. Sankar ${ }^{2}$
}

Received: 5 April 2015 / Accepted: 12 August 2015 / Published online: 20 August 2015

(C) Indian Association of Surgical Oncology 2015

\begin{abstract}
Adenoid cystic carcinoma is very rare, with an incidence of 0.1 to 0.26 per one lakh people. It is the second most common primary malignancy of the trachea. The etiology, clinical manifestation and prognosis of ACC trachea in Indian scenario has not been discussed so far. We evaluated the clinical presentation, treatment and follow up details of six patients with ACC of trachea, who were treated in our Institute from January, 2006 to October,2014. Cough with expectoration, exertional dyspnoea and haemoptysis were the most frequent presentations. Proximal trachea was involved in five patients with lesion extending to subglottis in two patients. The male: female ratio was equal and most patients presented in the 4th decade of their life. Two patients were treated with total laryngectomy with proximal tracheal resection, two with tracheal resection and anastomosis and one with window resection. Four patients who were treated surgically received post operative radiation. One patient with inoperable disease was treated with radical radiotherapy. All the patients are doing well with a median follow up period of 42.8 months.
\end{abstract}

Keywords Adenoid cystic carcinoma $\cdot$ Trachea

\section{Introduction}

The incidence of primary tracheal carcinoma is 0.1 to 0.26 per $1,00,000$ persons and accounts for $0.1-0.4 \%$ of all malignant diseases. Adenoid cystic carcinoma is the second most

Santhosh Kumar N

dr.santhosh82@gmail.com

Regional Cancer Centre, Thiruvananthapuram, Kerala, India

2 Sree Chitra Tirunal Institute for Medical Sciences \& Technology, Thiruvananthapuram, India common malignancy of the trachea. ACC of trachea arises from the submucosal glands and has an indolent course. Surgical excision is the main stay of the treatment, with radiotherapy can be used as an adjuvant to it. It has good prognosis, if diagnosed and treated at right time. We report six cases of adenoid cystic carcinoma of the trachea, treated in our institution from 2006 to 2014. The etiology, clinical features, treatment and the review of literature are discussed.

\section{Patients and Methods}

We are reporting a series of six cases of ACC of trachea treated in our institution, during the study period between January, 2006 to October, 2014. Among the six patients, three were males and three were females. The age of the patients ranged from 24 to 50 years and the mean age of presentation was 42.17 years. None of the patients were smokers. Two of these patients were doing rubber tapping; they were involved in extracting the rubber from rubber trees in the estates.

All the patients presented with symptoms of cough with expectoration of scanty sputum and exertional dyspnea. Five of them had at least one episode of haemoptysis at the time of presentation. Two patients had wheezing and were treated with bronchodilators by local physician for about 1 year. One patient had mild stridor that aggravated on exertion. None of these patients had dysphagia. One patient presented to our institute with recurrence after endoscopic LASER excision, followed by EBRT from outside. (Table 1)

Endoscopic evaluation, biopsy and CT evaluation was done for all six patients. Proximal trachea was involved in five patients with the lesion extending to the subglottis in two patients. Extratracheal spread was present in three patients with inoperable oesophageal involvement in one patient. Three of them had submucosal disease and among them one had circumferential submucosal disease. 
Table 1 Clinical presentation

\begin{tabular}{llllll}
\hline Patients & Cough with sputum & Haemoptysis & Exertional dyspnea & Wheezing & Stridor \\
\hline 1 & + & + & + & - & - \\
2 & + & + & + & - & - \\
3 & + & + & + & + & - \\
4 & + & + & + & + & - \\
5 & + & + & + & + & + \\
6 & + & - & & & - \\
\hline
\end{tabular}

Pretracheal and precarinal lymphnodes were enlarged in one patient and two of them had pulmonary metastasis. (Table 2)

Two patients were treated with total laryngectomy with proximal tracheal resection, two with tracheal resection and anstomosis and one with window resection. All these patients received post-operative radiotherapy except one patient who had already received EBRT from outside. One patient, for whom the lesion was extensive and was inoperable, was treated with radical radiotherapy (60Gy/30\#,IGRT). The two patients with laryngectomy were rehabilitated with tracheoesophageal voice prosthesis.

All these patients are being regularly followed up till date. All of them are disease free and none of them are having any symptoms. The mean follow up period is 42.8 months. One patient who was treated with radical radiotherapy, the treatment was completed on 29th August, 2014. She is having the shortest follow up period.

\section{Discussion}

The incidence of primary tracheal carcinoma is 0.1 to 0.26 per $1,00,000$ persons and accounts for $0.1-0.4 \%$ of malignant diseases. The squamous cell carcinoma is the most common malignancy of the trachea, followed by adenoid cystic carcinoma. Adult tracheal tumors are very rare and a review of tracheal tumors revealed that $80-90 \%$ were malignant. In a review article that constituted 352 cases by Price et al. squamous cell carcinoma constituted $51 \%$ and adenoid cystic carcinoma $31 \%$. The remaining rare histologies included adenocarcinoma, anaplastic carcinoma, small cell carcinoma, lymphoma, chondrosarcoma, mucoepidermoid carcinoma and carcinoid tumour [1-5].

Adenoid cystic carcinoma is a malignant tumor arising from the salivary glands and it occurs most commonly in the parotid gland. ACC constitutes around $10 \%$ of the head and neck tumors. ACC of the trachea is very rare and it arises from the submucosal glands of the trachea. ACC commonly arises at the distal one third of the trachea and the involvement of the proximal trachea and larynx are extremely rare [6].

But most of our patients had disease in the proximal trachea and only one patient had involvement of distal trachea.

Unlike SCC, Adenoid cystic carcinoma is not associated with smocking. Dohyung Kim et al. reported a case of tracheal ACC in a worker exposed to rubber fumes. Rubber fumes are generated during the compounding or curing process of tire manufacturing. Specific carcinogens associated with rubber fumes are not yet identified, but there are several reports describing the malignant potential of rubber fumes. Mancuso et al. reported that nitroso compounds can cause cancer in laboratory mice and the rubber fumes contain nitroso compounds. Thus they tried to explain the higher incidence of salivary gland cancer in rubber industrial workers. Vermeulenet al. proposed that some components of rubber fumes may have mutagenic potential [2,7-10].

Two of our patients were working in rubber estates. Though they were not working in rubber industry, they were associated with extracting raw rubber and its initial processing. We are not sure whether they were exposed to rubber fumes as told in the literature and the association may be coincidental.

Tracheal ACC presents more frequently in the fourth and fifth decades of life. It does not have any sex predilection and occurs in males and females at the same frequency. It has a low malignant potential and has a prolonged clinical course
Table 2 Site of involvement and metastases

\begin{tabular}{llllll}
\hline Patients & larynx & Proximal trachea & Distal trachea & Extra tracheal spread & Pulmonary metastasis \\
\hline 1 & + & + & - & + & + \\
2 & - & + & - & - & - \\
3 & + & + & - & - & - \\
4 & - & + & + & + & - \\
5 & - & + & - & + & - \\
6 & - & + & - & - & - \\
\hline
\end{tabular}




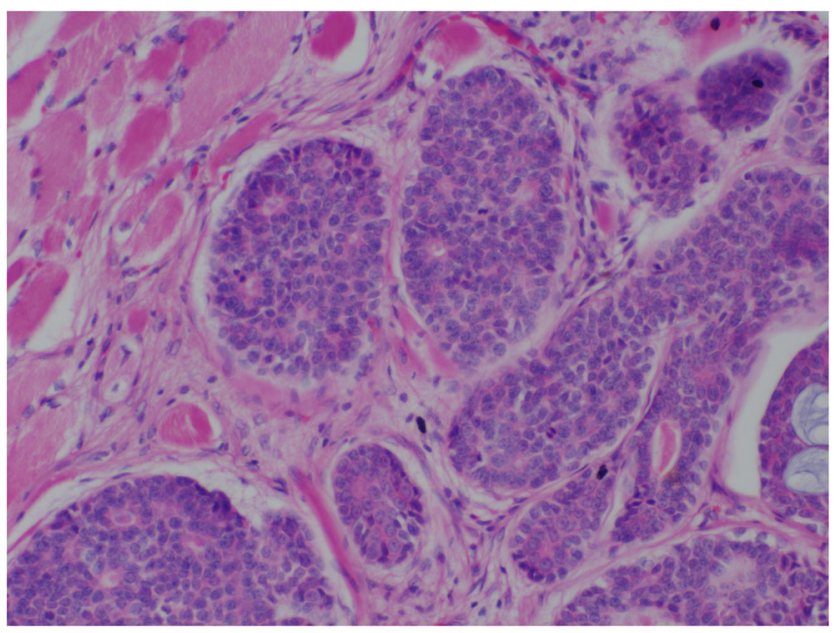

Fig. 1 H\&E Section 200x showing tumour cells arranged in nest with cribriform pattern

with late onset of metastasis and local recurrence. ACC spreads by direct extension submucosally or along perineural planes and the distant spread is via haematogenous route. Only $10 \%$ of the patients have regional lymphnode involvement or distant metastasis. The delicate arterial and lymphatic network accounts for lesser incidence of regional and distant metastasis at presentation. Pulmonary metastasis are the most common distant metastasis and may occur many years after the treatment [11-13].

Similar to the literature review, we had equal number of male and female patients and five of our patients were in the 4th decade of their life except one patient who was 24 years of age. Only one of our patients had lymph node metastasis and pulmonary metastasis.

ACC are more infiltrative in nature and form poorly defined sessile nodular growths and cause concentric narrowing of the airway. The histological subtypes include cribriform, tubular and solid forms. ACC of the trachea may present with signs and symptoms of upper airway obstruction like wheezing or stridor. It may also present with cough and haemoptysis due to mucosal irritation and ulceration. Only less than $25 \%$ of the patients may have haemoptysis in the early stages. The tracheal lumen has large functional reserve and thus the tumour may not cause any symptoms until they occlude 50$75 \%$ of the luminal diameter. Patients may present with non-specific symptoms of cough, wheezing or exertional dyspnoea that can mislead the physicians to have a diagnosis of asthma, COPD, URI etc. It can also invade the upper aerodigestive tract and can cause dysphagia [7, 14-16].

All of our patients presented with non-specific symptoms like cough with scanty sputum and exertional dyspnoea. In accordance with the literature review, two of them were initially misdiagnosed by the primary physician and were treated with bronchodilators. But against the above told evidences five of our patients had haemoptysis at least once.

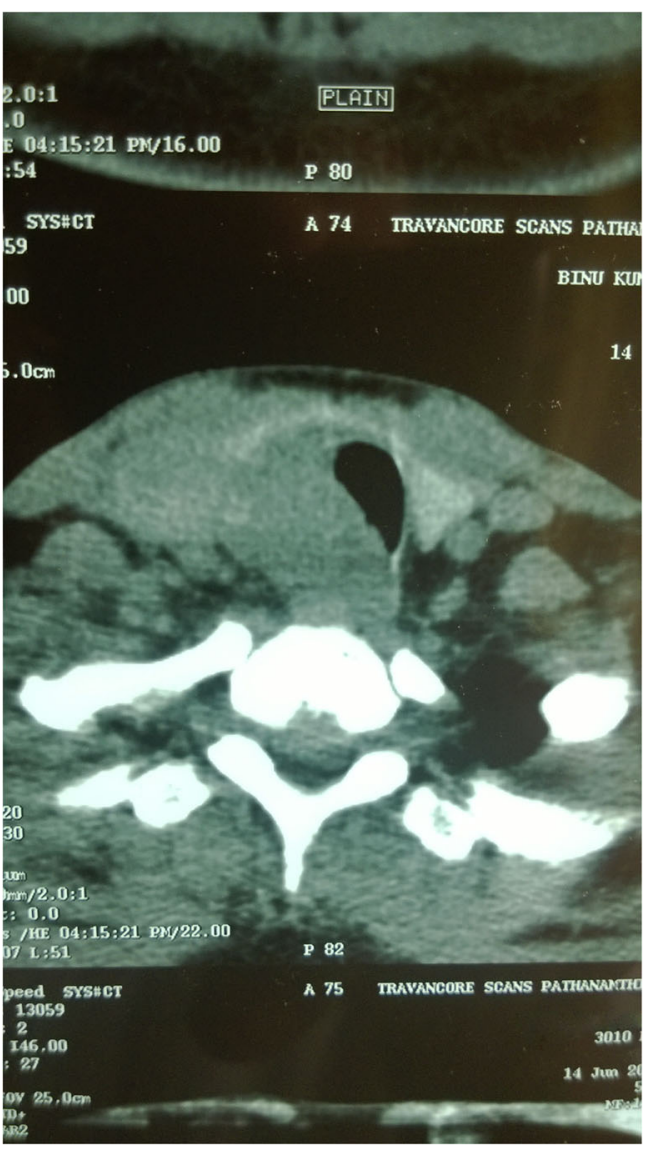

Fig. 2 CT Scan image showing the growth

The ACC of the trachea generally has good prognosis. According to Hadju et al. the average survival time is 9 years for ACC compared to 9 months for SCC. Over all 5 year survival is around $30 \%$, but it is reduced to $18 \%$ when there is extratracheal extension. All the patients with only intraluminal disease shows a 5 year survival rate of $50 \%$. Pulmonary metastasis can occur many years after the onset of primary disease and may remain asymptomatic for long period of time $[17,18]$.

All of our patients are doing well including those with extratracheal spread and the patient with metastasis.

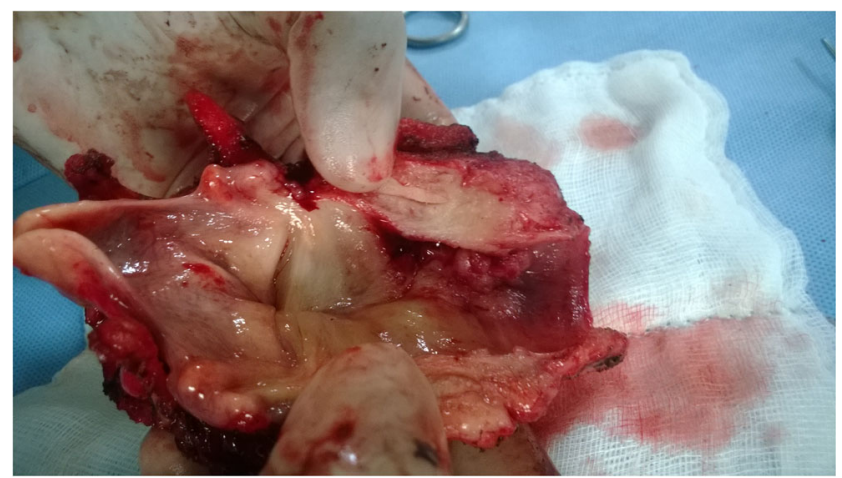

Fig. 3 Laryngectomy secimen showing growth in the subglottis and upper trachea 
Endoscopic evaluation, biopsy and imaging with CT scan are the standard investigations required. CT scan is the standard imaging modality recommended for assessing the intraluminal and extratracheal extension and its relationship with adjacent structures. MRI may be used, but does not have any distinct advantage over CT scan. Endoluminal ultrasound can detect the compression and infiltration of the trachea by an extrinsic tumor and is very useful in assessing the submucosal extension and thus can aid in avoiding a positive margin after resection $[1,19,20]$.

Treatment of ACC of trachea includes surgery, radiotherapy or both. Surgical resection followed by post-operative radiotherapy is the recommended treatment of choice. Various surgical procedures have been described including laryngectomy with resection of the upper trachea, tracheal resection (sleeve or window) and anastomosis, endoscopic resection or LASER excision etc. According to Grillo the criteria for nonresectability include the involvement of greater than 50-60\% of tracheal length, extension to the carina, or radiologically determined mediastinal extension. Lymphnodes should not be dissected extensively because that may compromise the blood supply to the remaining trachea. [21-23]

Radiotherapy is being used as an adjuvant after surgical resection or for unresectable tumors, medically inoperable cases or for palliation. Endotracheal brachytherapy is another option that improves local control after external beam radiotherapy. Muller et al. reported good survival rates after primary radiotherapy for ACC of trachea. A combination of carboplatin/ paclitaxel and radiotherapy was used effectively by Haddad and colleagues for unresectable head and neck ACC $[1,24,25]$ :

A complete resection gives good long term survival while incomplete resection is directly related with recurrence. Tumor depth, length and nodal status are not definite predictors of survival. Disease free survival after surgical resection is limited by distant metastasis and regional spread. A French cooperative study by Regnard et al. demonstrated a better survival after complete resection. Gaissert et al. reported that long term survival was significantly better with complete resection, negative airway margins and adenoid cystic carcinoma. But according to Maziak et al. there was no difference in survival between complete and incomplete resection [26-28].

\section{Conclusion}

Adenoid cystic carcinoma is a rare tumor and due to its low incidence, we may miss an early diagnosis and thus lead to a delay in the treatment. A good understanding of the clinicopathological profile may aid in clinical suspicion and diagnosis at an early stage. ACC has an indolent course and good prognosis; there for a radical treatment can be provided in spite of extra-tracheal spread and distant metastasis (Figs. 1, 2 and 3 ).

\section{References}

1. Macchiarini P (2006) Primary tracheal tumours. Lancet Oncol 7: 83-91

2. Bhattacharyya $\mathrm{N}$ (2004) Contemporary staging and prognosis for primary tracheal malignancies: a population-based analysis. Otolaryngol Head Neck Surg 131:639-42

3. Grillo HC. Surgery of the Trachea and Bronchi (2004) Pmph USA Ltd., Hamilton, Ontario

4. Shadmehr MB, Farzanegan R, Graili P, Javaherzadeh M, Arab M, Pejhan $S$ et al (2011) Primary major airway tumors; management and results. Eur J Cardiothorac Surg 39:749-54

5. Price JC, Percarpio B, Murphy PW, Henderson RL (1979) Recurrent adenoid cystic carcinoma of the trachea: intraluminal radiotherapy. Otolaryngol Head Neck Surg 87:614-623

6. Calzada AP, Miller M, Lai CK, Elashoff DA, Abemayor E, St John MA (2012) Adenoid cystic carcinoma of the airway: a 30-year review at one institution. Am J Otolaryngol 33:226-31

7. Desai DP, Holinger LD, Gonzales-Crussi F (1998) Tracheal neoplasm in children. Ann Otol Rhinol Laryngol 107:790-96

8. Kim D, Hwang Y, Choi S, Park C, Lee N, Kim EA (2013) A case of tracheal adenoid cystic carcinoma in a worker exposed to rubber fumes. Ann Occup Environm Med 25:22

9. Mancuso TF, Brennan MJ (1970) Epidemiological considerations of cancer of the gallbladder, bile ducts and salivary glands in the rubber industry. J Occup Med 12(9):333-341

10. Vermeulen R, Bos RP, de Hartog J, van Drooge H, Kromhout H (2000) Mutagenic profile of rubber dust and fume exposure in two rubber tire companies. Mutat Res 468(2):165-171

11. Ahn Y, Chang H, Lim YS, Hah JH, Kwon TK, Sung MW et al (2009) Primary tracheal tumors: review of 37 cases. J Thorac Oncol 4:635-8

12. Haresh KP, Prabhakar R, Rath GK, Sharma DN, Julka PK, Subramani V (2008) Adenoid cystic carcinoma of the trachea treated with PET-CT based intensity modulated radiotherapy. J Thorac Oncol 3:793-5

13. Grillo HC, Mathisen DJ (1990) Primary tracheal tumors: treatment and results. Ann Thorac Surg 49:69-77

14. Moran CA (1995) Primary salivary gland type tumours of lung. Semin Diag Pathol 12:106-22

15. Hollingsworth HM (1987) Wheezing and stridor. Clin Chest Med 8: 231-40

16. Geffin B, Grillo HC, Cooper JD, Pontoppidan H (1971) Stenosis following tracheostomy for respiratory care. JAMA 216:1984-88

17. Hajdu SI, Huvos AG, Goodner JT, Foote FW Jr, Beattie EJ Jr (1970) Carcinoma of the trachea. Clinicopathologic study of 41 cases. Cancer 25:1448-1456

18. Morrison MD, Salkeld U (1982) Prognostic factors in primary tracheal malignancy. J Otolaryngol 11:204-208

19. (2004) Cystic carcinoma of the airways: helical CT and histopathologic correlation. AJR Am J Roentgenol 183:277-81

20. Compeau CG, Keshavjee S (1996) Management of tracheal neoplasms. Oncologist 1:347-53

21. Azar T, Abdulkarim FW, Tucker HM (1998) Adenoid cystic carcinoma of trachea. Laryngoscope 108:1297-1300

22. Grillo HC (1981) Tumors of the cervical trachea. In: Suen JY, Myers EN (eds) Cancer of the Head and Neck. Churchill Livingstone, New York, pp 500-522

23. Parrish CM, Jones RE (1960) Primary tracheal tumors. Am Surg 26:95-98

24. Muller A, Stockamp B, Schnabel T (2000) Successful primary radiation therapy of adenoid cystic carcinoma of lung. Oncology 58:15-17

25. Haddad RI, Posner MR, Busse PM, et al (2006) Chemoradiotherapy for adenoid cystic carcinoma: preliminary results of an organ sparing approach. Am J Clin Oncol 153-157 
26. Regnard JF, Fourquier P, Levasseur P (1996) Results and prognostic factors in resections of primary tracheal tumors: a multicenter retrospective study. The French society of cardiovascular surgery. J Thorac Cardiovasc Surg 111:808-13

27. Gaissert HA, Grillo HC, Shadmehr MB, et al (2004) Long-term survival after resection of primary adenoid cystic and squamous cell carcinoma of the trachea and carina. Ann ThoracSurg 18961897

28. Maziak DE, Todd TR, Keshavjee SH, Winton TL, Van Nostrand P, Pearson FG (1996) Adenoid cystic carcinoma of the airway:thirty-two-year experience. J Thorac Cardiovasc Surg 112:1522-31 